\title{
Mediadores inflamatórios, citograma em lavado nasal e tomografia computadorizada de seios paranasais em crianças atópicas
}

\author{
Inflammatory mediators, cell counts in nasal lavage and computed tomography \\ of the paranasal sinuses in atopic children
}

\author{
Loreni C.S. Kovalhuk ${ }^{1}$, Nelson A. Rosário ${ }^{2}$, Arnolfo Carvalho ${ }^{3}$
}

\section{Resumo}

Objetivos: os objetivos deste estudo foram avaliar a celularidade e os mediadores inflamatórios no lavado nasal (LN) e a extensão de comprometimento da mucosa dos seios paranasais, em atópicos assintomáticos para sinusite.

Métodos: foram estudados 48 atópicos com rinite alérgica (RA), 33/48 com asma; 13 crianças não atópicas constituíram o grupo controle. Foram excluídos os casos com sinusite aguda, crônica ou recorrente. A extensão de lesão da mucosa paranasal, avaliada por tomografia computadorizada (TC) coronal dos seios da face (SF), foi graduada por escore padronizado (0-30). Escore maior ou igual a 12 indicava comprometimento extenso da mucosa dos SF. O LN foi obtido para quantificar a celularidade total e diferencial. Uma alíquota do sobrenadante foi usada para dosagem de mediadores inflamatórios: Interleucina-8 (IL-8), Mieloperoxidase (MPO), Proteína catiônica eosinofílica (ECP). A albumina foi usada como marcador de permeabilidade vascular. Estas determinações foram realizadas em amostras do fluido nasal (FN) de todos os atópicos e em 6/13 dos casos-controle. Foram realizados nos 3 grupos hemograma e espirometria.

Resultados: o comprometimento da mucosa paranasal foi extenso em 7/33 (21\%) dos asmáticos (Grupo I), 2/15 (13\%) dos pacientes com RA (Grupo II). No grupo controle (Grupo III) o maior escore de TC foi 7. A contagem total de células e de eosinófilos $/ \mathrm{ml}$ e a concentração de albumina do $\mathrm{FN}$ foram maiores entre asmáticos com escore de TC acima de 12. O nível de IL-8, o número de neutrófilos e de células epiteliais/ml no FN foram semelhantes nos 3 grupos. Os atópicos $(n=48)$ apresentaram uma correlação positiva entre escore de TC, eosinofilia periférica, número de eosinófilos $/ \mathrm{ml}$ e concentração de ECP no FN. Houve uma associação entre o número de neutrófilos e concentrações de IL-8 e MPO e entre IL-8 e eosinófilos.

Conclusões: em asmáticos assintomáticos para sinusite, o comprometimento extenso da mucosa paranasal está associado à eosinofilia periférica e do lavado nasal e à ativação celular. A infiltração e a ativação de neutrófilos não estavam relacionadas com a maior extensão de lesão da mucosa paranasal.

J Pediatr (Rio J) 2001; 77 (4): 271-8: sinusite, asma, rinite, tomografia computadorizada, lavado nasal, interleucina- 8 , mieloperoxidase, proteína catiônica eosinofílica.

\section{Abstract}

Objective: the aims of this study were to evaluate inflammatory cells, the profile of inflammatory mediators in nasal lavage (NL), and the involvement of the paranasal mucosa in atopic infants with no symptoms of sinusitis.

Methods: 48 atopic patients with allergic rhinitis (AR), and 33/ 48 patients with asthma were studied; the control group consisted of 13 nonatopic children. Those individuals with acute, chronic or recurrent sinusitis were excluded. The involvement of the paranasal mucosa was assessed by coronal computed tomography (CT) and graded by a standard protocol (0-30). A CT score greater than or equal to 12 indicated extensive involvement. Nasal lavage was used to quantify total and differential nasal cell counts. An aliquot of the supernatant was used for determining inflammatory mediators: interleukin-8 (IL-8), myeloperoxidase (MPO), and eosinophil cationic protein (ECP). Albumin was used as a marker for increased vascular permeability. These measurements were performed on all of the atopic patients and in 6/13 patients in the control group. The three groups were submitted to spirometry and complete blood cell count.

Results: extensive involvement of the paranasal mucosa was observed in $7 / 33(21 \%)$ of asthmatic patients (Group I) and 2/15 (13\%) of those with allergic rhinitis (Group II). The highest CT score in the control group (Group III) was 7. Total cell and eosinophil count $/ \mathrm{ml}$ and albumin concentration in nasal fluid were higher in asthmatic patients whose CT score was greater than 12. Interleukin8 concentration, number of neutrophils and epithelial cells $/ \mathrm{ml}$ in nasal fluid were similar in the three groups. A positive correlation between CT score, peripheral blood eosinophilia, number of eosinophils $/ \mathrm{ml}$ and eosinophil cationic protein concentration was found in the nasal fluid of atopic children $(n=48)$. There was an association between number of neutrophils and titers of interleukin- 8 and myeloperoxidase, and between interleukin- 8 and eosinophil count.

Conclusions: in asthmatic patients with no symptoms of sinusitis, the extensive involvement of the paranasal mucosa is associated with blood and nasal lavage eosinophilia and cellular activation. Neutrophil infiltration and activation were not related to increased involvement of the paranasal mucosa.

J Pediatr (Rio J) 2001; 77 (4): 271-8: sinusitis, asthma, rhinitis, computed tomography, nasal lavage, interleukin- 8 , myeloperoxidase, eosinophil cationic protein.

1. Mestre em Pediatria, Médica do Serviço de Alergia e Imunologia Pediátrica, Hospital de Clínicas, Universidade Federal do Paraná.

2. Professor Titular do Depto. de Pediatria, Univ. Federal do Paraná.

3. Professor Assistente de Radiologia do Hospital de Clínicas, Univ. Federal do Paraná. 


\section{Introdução}

A sinusite é definida como um processo inflamatório de um ou mais seios paranasais e freqüentemente está associada à rinite alérgica (RA) e à asma ${ }^{1}$. No entanto, não há descrição de estudo para determinar a incidência de sinusite bacteriana em pacientes alérgicos e não alérgicos e se pacientes alérgicos apresentam doença mais grave ou mais extensa que indivíduos não alérgicos ${ }^{2}$.

A sinusite pode coexistir com a asma ou desencadeá-la, porém ainda não está claro o mecanismo exato responsável por essa associação; além disso, a falta de uniformidade para o diagnóstico de sinusite leva a estudos com resultados conflitantes ${ }^{3}$. Crianças alérgicas com sintomas respiratórios crônicos apresentam elevada incidência de alterações radiológicas dos seios da face, desde espessamento mucoso à presença de nível líquido ou opacificação ${ }^{4}$. Entretanto, pacientes asmáticos muitas vezes apresentam alterações inflamatórias crônicas da mucosa paranasal, o que dificulta o diagnóstico de sinusite bacteriana em atópicos, especialmente os asmáticos. Portanto, deve-se ter em mente que nem todo exame radiológico anormal, seja o convencional, seja a tomografia computadorizada (TC) de seios da face, representa infecção bacteriana ${ }^{5,6}$.

A TC de seios da face por cortes coronais é o método de escolha para avaliação dos seios paranasais, delineando a unidade osteomeatal e seios etmoidais, os quais são importantes na fisiopatologia da sinusite, além de estabelecer a extensão de comprometimento da mucosa paranasal ${ }^{7}$.

A histologia da mucosa nasal é semelhante à das vias aéreas inferiores. A mucosa nasalé um local de fácil acesso, o que permite o estudo do processo alérgico, especialmente em crianças 8,9 .

A citologia quantitativa do lavado nasal (CQLN) auxilia na investigação da rinite, porém a técnica é complexa, dispendiosa e demorada ${ }^{10}$. A CQLN foi simplificada e avaliada quanto a precisão e acurácia, além de ser comparada à contagem diferencial em esfregaço nasal ${ }^{11}$.

Pelos relatos de ser a sinusite um agravante ou mesmo um desencadeante de asma, é frequente o uso de antibióticos em pacientes alérgicos com sintomas respiratórios crônicos. Por outro lado, há uma elevada freqüência de alterações radiológicas dos seios da face em pacientes com asma e/ou rinite alérgica, mesmo sem sinusite infecciosa. Esses fatos levam ao questionamento do uso prolongado de antibióticos nestes pacientes, visto que há relatos de melhora mesmo sem o uso dos mesmos ${ }^{2}$.

Foi proposto o presente estudo, em crianças com asma persistente e/ou rinite alérgica perene, assintomáticas para sinusite infecciosa, com o intuito de avaliar a relação da celularidade e dos mediadores inflamatórios no lavado nasal com a extensão das alterações tomográficas da mucosa paranasal.

\section{População e Métodos}

Foram selecionados consecutivamente 48 pacientes atópicos em acompanhamento no ambulatório de Alergia e Imunologia Pediátrica do Hospital de Clínicas da Universidade Federal do Paraná (UFPR). Os 48 atópicos tinham rinite alérgica (RA); 33/48 com asma associada à RA, todos com teste cutâneo positivo para o ácaro D. pteronyssinus.

O grupo controle incluiu 13 crianças não atópicas, acompanhadas no serviço de neuropediatria, submetidas à TC de crânio para investigação de epilepsia. Este grupo foi avaliado quanto a sintomas e sinais de RA e/ou asma por anamnese e exame físico, além do critério de teste cutâneo alérgico negativo para afastar atopia. Foram recrutados para este estudo crianças com idade mínima de 8 anos, colaborativas para os exames de função pulmonar, tomografia de seios da face e do lavado nasal.

Os 61 casos estudados foram agrupados pelo diagnóstico e pelo escore de TC. O grupo I incluiu pacientes com asma e rinite alérgica ( $n=33$ ), o grupo II, pacientes com rinite alérgica $(n=15)$, e o grupo III foi constituído por crianças não atópicas $(\mathrm{n}=13)$.

Foram excluídos os casos com história de sinusite recorrente ou crônica, caracterizada por odinofagia, secreção purulenta nasal e pós-nasal, congestão nasal e tosse produtiva noturna ${ }^{4}$; infecção de vias aéreas superiores e inferiores, respectivamente nas 2 e 4 semanas prévias à realização da TC e espirometria; presença de obstrução mecânica à rinoscopia; uso de corticóide tópico ou sistêmico, respectivamente 1 e 2 meses prévios ao estudo e de antihistamínico na semana anterior ao estudo.

Foi coletado sangue para hemograma; a partir de 350 células $/ \mathrm{mm}^{3}$ considerou-se eosinofilia ${ }^{12}$. A espirometria foi feita em espirômetro eletrônico (Spirosift 3000; Fukuda Denshii, Japan), e o volume expiratório forçado do primeiro segundo $\left(\mathrm{VEF}_{1}\right)$ foi expresso como percentual do previsto ${ }^{13}$.

Durante a avaliação, os pacientes apresentavam sintomas de asma e rinite alérgica, caracterizados respectivamente pela recorrência de tosse seca, sibilância e/ou dispnéia e de prurido nasal, espirros, coriza e/ou obstrução nasal ${ }^{14}$. A rinite não foi tratada, e a asma foi manejada com o uso regular de teofilina $(5 \mathrm{mg} / \mathrm{kg} / \mathrm{dose}) 3$ vezes ao dia e broncodilatador sob demanda.

Foi realizado estudo por tomografia computadorizada (TC) coronal dos seios da face, desde o seio frontal ao esfenoidal, incluindo a cavidade nasal. Os exames foram avaliados por radiologista sem conhecimento dos dados clínicos dos pacientes. Foi empregado um escore padronizado para avaliação da extensão de comprometimento da mucosa dos seios paranasais. Neste as áreas avaliadas foram divididas em cavidade nasal, complexo osteomeatal $(\mathrm{COM})$ e os seios paranasais. Na região dos seios parana- 
sais, cada seio era avaliado individualmente quanto à espessura máxima da mucosa, medida em milímetros, e uma pontuação de 0 a 3 era designada de acordo com o espessamento da mucosa. A quantificação das regiões do COM e passagem nasal recebiam pontuação 0 para ausência de lesão, 1 para comprometimento mínimo, 2 para moderado e 3 para extenso envolvimento de mucosa. A pontuação máxima possível era de 30 pontos ( 21 dos seios da face, 6 do COM e 3 da passagem nasal). O somatório do escore de TC foi usado para agrupar os pacientes pela extensão de lesão da mucosa paranasal. Escore de 0 a 11 indicava doença limitada e escore maior ou igual a 12 doença extensa ${ }^{15,16}$.

O lavado nasal (LN) foi feito por técnica previamente descrita por Bascom et al. ${ }^{10}$, a qual adaptamos para crianças. Para a coleta do fluido nasal (FN), o paciente mantinha a cabeça em extensão em torno de $30^{\circ}$; ocluindo a rinofaringe com o pálato mole, instilava-se fracionadamente $5,5 \mathrm{ml}$ de solução salina em cada narina; após 10 segundos o paciente fletia a cabeça, e o material era coletado em tubo cônico graduado, o qual era mantido no gelo durante o procedimento da coleta e, em seguida, registrava-se o volume recuperado ${ }^{10,17}$.

Procedia-se à homogeneização do $\mathrm{FN}$ por agitação vigorosa do material e centrifugação a $4^{\circ} \mathrm{C}(1.000 \mathrm{~g} / 5 \mathrm{minu}-$ tos $)^{10}$. Uma alíquota do sobrenadante foi estocada a $-80^{\circ} \mathrm{C}$ para determinação de mediadores inflamatórios e citocinas. O sedimento obtido era suspenso em $10 \mathrm{ml}$ de solução salina tamponada com fosfato (PBS), agitado e centrifugado a $4{ }^{\circ} \mathrm{C}(1.000 \mathrm{~g} / 15$ minutos $)$. Media-se o volume final do segundo sedimento, e uma alíquota de $10 \mu \mathrm{l}$ era usada para preencher a câmara de contagem do hemocitômetro de Neubauer para contagem do número total de células por mililitro em microscópio com aumento de 100X ou de 400X. Caso a amostra fosse muito concentrada, o material era novamente diluído para a contagem do número total de células/ml a partir da seguinte fórmula:

Número total de células/ml $=$ [(Número de células contadas), (Número de quadrados contados)] x [Fator de conversão da câmara de contagem] x [Fator de diluição]

O fator de conversão da câmara de contagem do hemocitômetro de Neubauer era de 10.000. O fator de diluição resultava da razão entre o volume final e o volume inicial do sedimento ${ }^{18}$.

À diluição do sedimento em PBS a concentração de células era ajustada para 500 células/ $\mu l$. Desta amostra, uma alíquota de $200 \mu$ l era centrifugada (Citocentrífuga LABHO CT-12) a 600 rpm por 6 minutos para obtenção das lâminas, as quais foram coradas pelo método de May-GrünwaldGiemsa para contagem diferencial de 100 células em microscópio com aumento 400x ou 1.000x. A leitura das lâminas foi feita por um patologista, sem o conhecimento dos dados clínicos dos pacientes, acompanhado pelo investigador. $\mathrm{O}$ número total $/ \mathrm{ml}$ de cada tipo celular foi calculado pelo produto da contagem total de células/ml e a fração obtida no diferencial ${ }^{10,11,19}$.
O método de detecção e quantificação da concentração de albumina no $\mathrm{FN}$ foi o radioimunoensaio competitivo com albumina marcada com I ${ }^{125}$ (DPC-Diagnostic Products Corporation - Los Angeles, CA). A concentração de mieloperoxidase (MPO) no FN foi medida por radioimunoensaio (Pharmacia \& Upjohn Diagnosis - Uppsala, Sweden). A concentração da proteína catiônica eosinofílica (ECP) foi determinada pela técnica de Fluoroenzima-imunoensaio (FEIA - Pharmacia CAP System- Uppsala, Sweden). A concentração de Interleucina-8 (IL-8) foi medida pela técnica quantitativa de imunoensaio enzimático com duplo anticorpo (R\&D Systems - Minneapolis, MN).

Foi empregada a análise de variância (ANOVA) para pesquisa de diferenças dentro e entre os grupos. A comparação da contagem de células total e diferencial dos mediadores e citocinas do lavado nasal foi feita pelo teste de Mann Whitney, entre grupos não pareados. A pesquisa de correlação foi feita pelo teste de Spearman. Foi empregado o teste exato de Fisher com correção de Yates para a análise de diferenças entre proporções. O nível de significância considerado foi de $5 \%$. O programa estatístico usado foi o Statistica versão 4.2.

Este estudo foi aprovado pela Comissão de Ética do Hospital de Clínicas - UFPR, e a participação dos pacientes no estudo estava condicionada à concordância e assinatura dos responsáveis aos termos do consentimento informado.

\section{Resultados}

Os 61 casos estudados foram agrupados pelo diagnóstico e pelo escore de TC. O grupo I incluiu pacientes com asma e rinite alérgica ( $n=33)$; o grupo II, pacientes com rinite alérgica $(n=15)$, e o grupo III foi constituído por crianças não atópicas $(n=13)$. A média e os limites de idade em anos dos pacientes nos grupos I, II e III foi de respectivamente 11,6 a (9-15); 11,7a (8,8 a 14,5) e 11,8a (8 a 14); a distribuição pelo sexo (Feminino/Masculino) foi 11/22, $5 / 10$ e $3 / 10$.

Os limites do escore padrão de TC dos seios da face eram de 0 a 30 . Doença paranasal extensa, ou seja, escore de TC maior ou igual a 12 , foi encontrada em $7(21 \%)$ dos pacientes do grupo I, e em 2 (13\%) do grupo II. Todos os casos do grupo 3 apresentaram escore inferior a 12 (Figura 1). As variações anatômicas presentes não se associaram à extensão de lesão à TC dos seios da face.

Os atópicos apresentaram eosinofilia, a qual foi significativamente maior entre os asmáticos. Houve uma correlação positiva $\left(\mathrm{r}_{\mathrm{s}}=0,41 ; \mathrm{p}=0,004\right)$ entre eosinofilia periférica e extensão de comprometimento de mucosa à TC (Figura 2).

No grupo I a distribuição dos pacientes de acordo com a gravidade da asma, nas categorias leve ou moderada persistente foi respectivamente de 24 e 9 casos; nenhum paciente apresentava asma de grave intensidade. Os limites de VEF1 no grupo I foram de 61 a 107\%. A média do VEF1 

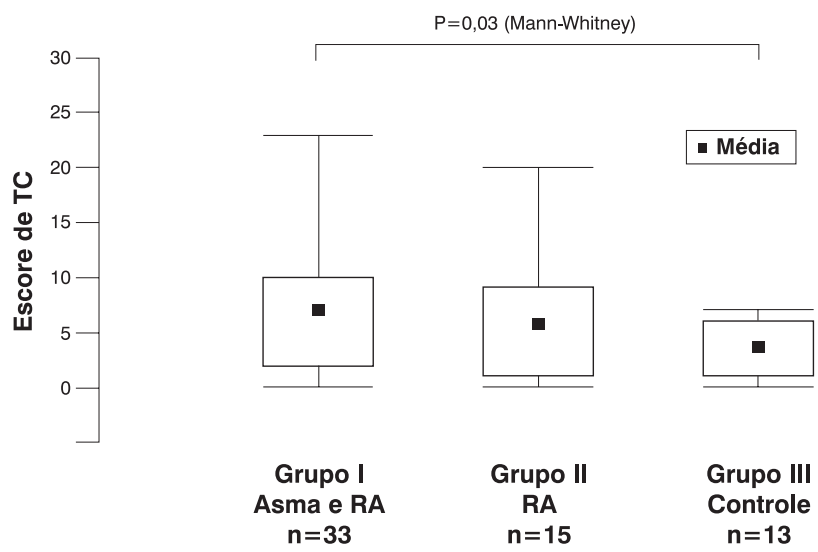

Figura 1 - Box \& Whisker Plot: Escore de tomografia computadorizada dos seios da face por grupos

foi menor no grupo com asma e rinite alérgica, se comparada à do grupo controle. O VEF1 não foi diferente entre asmáticos com escore de TC maior ou menor que 12. Os grupos RA e controle foram semelhantes quanto ao VEF1.

$\mathrm{O} \mathrm{LN}$ foi realizado em todos os pacientes, e o fluido nasal (FN) recuperado foi analisado quanto ao número total e diferencial de células $/ \mathrm{ml}$. Foi semelhante o percentual de volume de FN recuperado nos três grupos. A análise dos mediadores inflamatórios foi realizada no FN de todos os atópicos e em 6/13 dos casos do grupo controle.

$\mathrm{O}$ número total de células/ml recuperadas no $\mathrm{FN}$ dos pacientes com asma $\mathrm{RA}$ foi significativamente superior ao dos pacientes do grupo controle. Não houve diferença entre os grupos RA e controle (Tabela 2). A celularidade total foi maior no subgrupo dos asmáticos (mediana $=1.322$ células/ $\mathrm{ml})$ com lesão extensa à TC.

Os atópicos apresentaram predomínio de eosinófilos no FN e uma correlação positiva entre escore de TC e número de eosinófilos/ml (Figura 2). Não houve correlação do escore de TC dos seios da face com as demais células da contagem diferencial, nem com a celularidade total $/ \mathrm{ml}$ de FN. O número total de neutrófilos/ml foi semelhante nos três grupos. $\mathrm{O}$ número total de células epiteliais $/ \mathrm{ml}$ foi maior no grupo asma e RA, em comparação com o grupo RA. Os grupos RA e controle foram semelhantes quanto à contagem total de células epiteliais/ml (Tabela 2).

O número total de eosinófilos/ml foi significativamente maior nos asmáticos com comprometimento mucoso extenso $($ mediana $=912$ eosinófilos $/ \mathrm{ml})$, em comparação com os demais grupos, inclusive os asmáticos com escore de TC de seios da face inferior a 12 (mediana $=309$ eosinófilos $/ \mathrm{ml}$ ). O número total de neutrófilos e o de células epiteliais/ml de FN foi semelhante em todos os subgrupos, independente da extensão de comprometimento da mucosa paranasal à TC de seios da face.

À análise inicial de mediadores inflamatórios e citocinas mostrou diferença apenas no nível de MPO, o qual foi maior no grupo controle em comparação com os asmáticos. Ao se considerar os grupos pelo escore de TC, esta diferença se manteve apenas entre o grupo controle e os asmáticos com escore de TC inferior a 12. O nível de albumina do FN foi maior no grupo dos asmáticos com escore de TC de seios

Tabela 1 - Contagem de eosinófilos periféricos e parâmetros de função pulmonar nos 3 grupos

\begin{tabular}{|c|c|c|c|}
\hline Grupo & $\mathbf{n}$ & $\begin{array}{c}\text { Eosinófilos }{ }^{\dagger} \\
\left(/ \mathbf{m m}^{\mathbf{3}}\right)^{*}\end{array}$ & $\begin{array}{l}\text { VEF1 }^{\S} \\
(\%)^{* *}\end{array}$ \\
\hline Asma e RA (I) & 33 & $686 \pm 520$ & 83 \\
\hline RA (II) & 15 & $409 \pm 364$ & 89 \\
\hline Controle (III) & 13 & $148 \pm 94$ & 91 \\
\hline
\end{tabular}

Tabela 2 - Contagem do número total e diferencial de células x $10^{3}$ no fluido nasal dos três grupos

\begin{tabular}{|c|c|c|c|c|c|}
\hline \multirow[t]{3}{*}{ Grupo } & \multirow[t]{3}{*}{$\mathbf{n}$} & \multicolumn{4}{|c|}{ Fluido nasal (Número de células x $\left.10^{3}\right)$ † } \\
\hline & & \multirow{2}{*}{$\begin{array}{c}\text { Total de } \\
\text { células/ml* }\end{array}$} & \multicolumn{3}{|c|}{ Diferencial } \\
\hline & & & Eos $/ \mathrm{ml}^{* *}$ & Neut/ml & C.epit/ml*** \\
\hline I Asma e RA & 33 & 856 & 423,4 & 92,9 & 137,5 \\
\hline II RA & 15 & 422 & 177,1 & 92,5 & 55,1 \\
\hline III & 13 & 390 & 6,1 & 167,3 & 113,5 \\
\hline
\end{tabular}

¥ Mediana

* Grupo I x Grupo III, $p<0,01$;

** Grupo I x Grupo III, p<0,0001; Grupo II x Grupo III, p<0,001

*** Grupo I x Grupo II, $p<0,04$ 

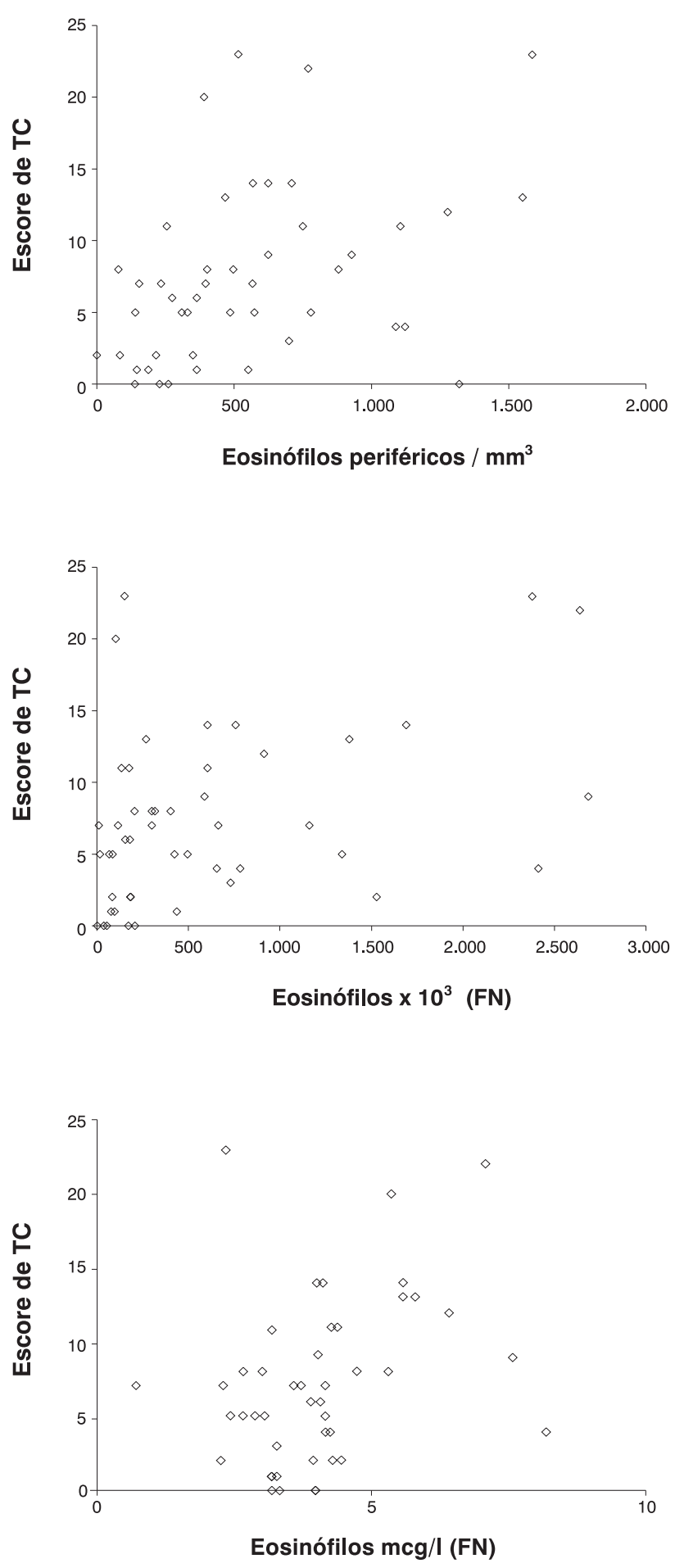

Figura 2 - Correlação entre escore de TC e eosinófilos periféricos, eosinófilos e ECP no FN

da face superior a 12 (mediana $=85)$, em comparação com o do grupo controle (mediana $=45$ ). A concentração de ECP no FN dos pacientes deste estudo apresentou ampla faixa de variação. A ECP foi significativamente maior no grupo dos asmáticos com escore de TC de seios da face superior a 12 (mediana $=266$ ), mas apenas quando comparada ao subgrupo dos pacientes com RA e escore de TC inferior a 12. AECP foi detectada no FN de indivíduos normais, porém com menor amplitude que nos demais grupos (Tabela 3).

Os níveis de IL-8 no FN foram semelhantes nos três grupos, a despeito da extensão de comprometimento da mucosa paranasal à TC de seios da face.

$\mathrm{O}$ escore de TC de seios da face se associou à ECP (Figura 2). À análise da contagem diferencial de células, somente os eosinófilos/ml apresentaram relação direta com as determinações de albumina $\left(r_{s}=0,49, p<0,001\right)$ e ECP $\left(r_{s}\right.$ $=0,55, \mathrm{p}<0,0001)$.

\section{Discussão}

As rinossinusites estão entre as doenças crônicas mais freqüentes, comumente associadas à rinite alérgica, com elevada taxa de morbidade e custo do tratamento ${ }^{1}$.

Em crianças com asma atópica, freqüentemente com rinite alérgica associada, é comum a ocorrência de alterações em estudos radiológicos dos seios da face, paralelamente a sintomas persistentes de vias aéreas superiores, simulando sinusite crônica, mesmo sem infecção associada.

Pelikan \& Pelikan-Filipek, à investigação por exame radiológico de seios da face pré e pós-provocação nasal com alérgeno, encontraram acentuação do espessamento da mucosa e opacificação dos seios paranasais em 32/73 pacientes e demonstraram a relação entre sinusite e rinite alérgica $^{20}$.

No presente estudo, 2/15 (13\%) dos pacientes com RA perene apresentaram comprometimento mucoso extenso à $\mathrm{TC}$ de seios da face. Os pacientes dos grupos asma e rinite (Grupo I) e rinite alérgica (Grupo II) apresentavam rinite ativa; portanto, o que os diferenciou foi a presença ou ausência de asma. Nesta casuística, por ser o envolvimento da mucosa paranasal mais extenso nos pacientes do grupo I, atribuímos à variável asma, independente de sua gravidade, o maior comprometimento da mucosa paranasal, o que poderia refletir uma maior extensão da reação inflamatória da mucosa respiratória.

A incidência estimada de sinusite em asmáticos é de $40 \%$ a $75 \%$. Embora estudos evidenciem que a sinusite precipita ou piora a asma, questiona-se se ambas apenas coexistam e representem o órgão alvo de um mesmo processo inflamatório ocorrendo em diferentes porções do aparelho respiratório ${ }^{1}$.

Pfister e colaboradores encontraram, em $74 \%$ dos asmáticos, espessamento mucoso à $\mathrm{TC}$ de seios da face classificado como mínimo. A sinusite aguda não foi co- 
Tabela 3 - Mediadores inflamatórios no fluido nasal em indivíduos dos três grupos

\begin{tabular}{lccccc}
\hline Grupo & \multirow{2}{*}{} & \multicolumn{2}{c}{ Fluido nasal } \\
& & Albumina (mcg/l) & ECP (mcg/l) & MPO (mcg/l)* & IL-8 (pg/ml) \\
\hline I (Asma e RA) & 33 & $74(10-205)$ & $55(2-3614)$ & $246(12-612)$ & $831(66-2245)$ \\
II (RA) & 15 & $57(6,6-402)$ & $41(0,02-266)$ & $112(12-1368)$ & $692(103-4000)$ \\
III & 6 & $45(12-98)$ & $34(5-124)$ & $427(195-846)$ & $1243(513-2488)$ \\
\hline
\end{tabular}

¥ Mediana (Limites)

* MPO: Grupo I x Grupo III, p=0,03

mum ${ }^{5}$

O espessamento de mucosa paranasal também foi freqüente à investigação de 100 asmáticos com sintomas persistentes de vias aéreas superiores submetidos a exame radiológico dos seios da face. Espessamento superior a $6 \mathrm{~mm}$ se associou a tosse produtiva e sinusite bacteriana, o que não ocorreu quando inferior a $2 \mathrm{~mm}$, fato que os autores consideraram indicativo de sinusopatia alérgica ${ }^{21}$.

A relação entre gravidade de asma e exame radiológico de seios da face anormal foi avaliada em 138 crianças que apresentavam desde tosse equivalente de asma a asma grave. Alterações da mucosa sinusal ocorreram em $27 \%$ a $36 \%$, porém sem associação com gravidade de asma ${ }^{22}$.

O grau de hiperreatividade brônquica (HRB) inespecífica à metacolina reflete a gravidade da asma. Entre asmáticos com sinusite infecciosa, a HRB foi maior do que em asmáticos sem sinusite, a qual diminuiu após o tratamento da sinusite, paralelamente à melhora radiológica e dos sintomas de asma ${ }^{23}$.

Os resultados deste estudo evidenciam entre os atópicos, em especial os asmáticos $(21 \%)$, uma propensão a apresentar lesão de mucosa paranasal extensa, sem resultar em maior gravidade de asma ou de obstrução ao fluxo aéreo. Escore de TC igual a zero foi encontrado em apenas 2/33 (6\%) dos asmáticos. Estes achados sugerem que, entre asmáticos assintomáticos para sinusite infecciosa, é comum o envolvimento de mucosa paranasal sem que isso resulte em piora da asma. Nesta casuística, porém, foram avaliados apenas pacientes com asma de leve a moderada intensidade, por constituírem a maioria dos casos em acompanhamento no ambulatório ${ }^{24}$. Além disso, o uso de corticóide sistêmico, para manejo de asma grave, foi critério de exclusão do presente estudo.

A divergência dos resultados da literatura quanto às investigações da relação entre sinusite e asma em crianças podem ser atribuídas a falhas no planejamento, randomização e ausência de grupo controle, além da falta de unifomidade nos critérios diagnósticos e de não se considerar a variabilidade de apresentação clínica da asma na criança ${ }^{25}$.

Newman e colaboradores, à investigação de adultos com sinusite crônica, encontraram associação entre asma e eosinofilia nos casos com extenso comprometimento de mucosa paranasal à TC. Eosinofilia foi o fator determinante da extensão de lesão mucosa, mesmo entre não atópicos ${ }^{16}$.

Nesta casuística, atópicos assintomáticos para sinusite, com asma e/ou rinite alérgica, apresentaram uma associação entre extensão de lesão mucosa à TC e eosinofilia periférica, sugerindo uma participação dos eosinófilos na extensão de lesão, principalmente entre asmáticos.

Um conceito recente é o da continuidade das vias respiratórias; assim, processos inflamatórios de vias aéreas superiores podem tanto interferir quanto refletir os de vias aéreas inferiores, com base em estudos histológicos com material de biópsia nasal e endobrônquica de asmáticos que revelam uma infiltração eosinofílica da mucosa paranasal muito semelhante à encontrada na asma ${ }^{26,27}$.

A mucosa nasal representa um local de fácil acesso para estudo do processo inflamatório alérgico; a intensidade deste se reflete no fluido do lavado nasal e fornece um paralelo entre sintomas do trato respiratório superior e inferior ${ }^{9}$. A CQLN simplificada tem aplicação na investigação clínica, por ser um método quantitativo da celularidade da mucosa nasal. No entanto, ainda não está estabelecido um padrão de normalidade, o que torna difícil a comparação entre resultados de estudos ${ }^{11}$.

Observamos que a celularidade no FN não diferenciou pacientes com maior escore de TC. Encontramos neutrofilia relativa (percentual), mas não absoluta no $\mathrm{FN}$ dos casos controle, porém com valores inferiores aos observados em IVAS $^{11}$. A presença de neutrófilos no $\mathrm{FN}$ pode diagnosticar rinossinusite infecciosa, porém neutrofilia na secreção nasal pode ocorrer em indivíduos normais ${ }^{28}$.

A eosinofilia da secreção nasal auxiliou na diferenciação dos asmáticos com maior extensão de comprometimento de mucosa à TC, até mesmo do subgrupo com menor 
extensão de lesão.

Noah e colaboradores não encontraram diferença no grau de eosinofilia do FN, ao compararem alérgicos não asmáticos com alérgicos asmáticos, porém todos assintomáticos durante a avaliação ${ }^{9}$.

Na mucosa respiratória de pacientes alérgicos e asmáticos, células inflamatórias e estruturais, estão envolvidas na produção de citocinas e mediadores inflamatórios que mantêm a inflamação crônica e a hiperreatividade da via aérea $^{29,30}$.

A concentração de albumina no FN é um dos parâmetros de permeabilidade vascular ${ }^{9}$. Nesta casuística, a concentração de albumina no FN foi maior no grupo asma e RA (Grupo I) com lesão extensa à TC. Somente a contagem de eosinófilos foi proporcional à concentração de albumina, $\mathrm{o}$ que pode refletir uma relação entre aumento da permeabilidade vascular, afluxo de células inflamatórias, principalmente eosinófilos.

No estudo de Noah e colaboradores, os níveis de IL-8 no FN foram elevados em asmáticos, em comparação com os alérgicos não asmáticos e os não atópicos, todos assintomáticos durante o período de avaliação ${ }^{9}$. Também foi observada elevação de IL-8 no FN em exacerbação da asma por IVAS, independente de atopia ${ }^{31}$.

Além das diferenças de método e casuística desses estudos, nossos pacientes usavam teofilina oral em dose baixa e broncodilatador sob demanda. $\mathrm{O}$ uso de teofilina oral pode ter interferido na avaliação de mediadores do FN. Naclerio e colaboradores descreveram uma redução da liberação de histamina no $\mathrm{FN}$, simultaneamente à de outros mediadores, o que pode decorrer de um efeito das xantinas sobre a ativação de mastócitos e basófilos ${ }^{32}$.

A infiltração eosinofílica da mucosa respiratória é característica da rinite alérgica e da asma, bem como a liberação de proteínas citotóxicas derivadas de seus grânulos, como a proteína catiônica eosinofílica (ECP) e a proteína básica maior $(\mathrm{MBP})^{33}$. A lesão do epitélio respiratório no asmático é proporcional à infiltração eosinofílica e à liberação de ECP e $\mathrm{MBP}^{34}$. Os indivíduos asmáticos apresentam níveis significativamente maiores de IL-8 e ECP no fluido do lavado nasal em comparação com pacientes atópicos, porém não asmáticos, e com indivíduos normais 9 .

Havia uma correlação positiva entre o escore de TC, a contagem de eosinófilos e a concentração de ECP no FN. Assim uma maior extensão de comprometimento de mucosa à TC de seios da face, se associou tanto à eosinofilia quanto à ativação dos eosinófilos no $\mathrm{FN}$, sugerindo que a lesão da mucosa paranasal fosse secundária à inflamação eosinofílica.

Esses dados indicam que asmáticos assintomáticos para sinusite apresentam maior extensão de comprometimento de mucosa paranasal, o que pode sugerir que se trata de um único processo inflamatório presente em diferentes níveis do aparelho respiratório.

Embora não apresentassem quadro clínico de sinusite, não podemos afirmar que nossos casos não tivessem infecção dos seios paranasais. Por outro lado, o diagnóstico radiológico de sinusite em pacientes alérgicos não implica em tratamento com antibióticos por período prolongado de tempo, pois deve-se considerar que o comprometimento da mucosa dos seios paranasais pode acompanhar a reação inflamatória alérgica das vias respiratórias, e não necessariamente um processo infeccioso. A implicação prática dos resultados aqui apresentados é a necessidade de um adequado tratamento da alergia respiratória de pacientes atópicos, previamente à investigação por imagem de sinusite infecciosa e indicação de uso prolongado de antibióticos nestes pacientes.

\section{Agradecimentos}

Ao professor Álvaro Cruz pela orientação na técnica de citologia quantitativa do lavado nasal e ao professor Gilberto Sampaio pelo auxílio na leitura das lâminas.

\section{Referências bibliográficas}

1. Spector SL, Bernstein IL, Li JT, Berger WE, Kaliner MA, Schuller DE, et al. Parameters for the diagnosis and management of sinusitis. J Allergy Clin Immunol 1998; 102:S117-S144.

2. Dohlman AW, Hemstreet MP, Odrezin GT, Bartolucci AA. Subacute sinusitis: Are antimicrobials necessary? J Allergy Clin Immunol 1993; 91:1015-23.

3. Borts MR, Slavin RG. Sinusitis and asthma. In: Sinusitis Pathophysiology and Treatment. New York: Marcel Dekker; 1994. p.159-74.

4. Rachelefsky GS, Goldberg M, Katz RM, Boris G, Gyepes MT, Shapiro MJ, et al. Sinus disease in children with respiratory allergy. J Allergy Clin Immunol 1978; 61:310-14.

5. Pfister R, Lütolf FM, Schapowal A, Glatte B, Schmitz M, Menz G. Screening for sinus disease in patients with asthma: A computed tomography-controlled comparison of A-mode ultrasonography and standard radiography. J Allergy Clin Immunol 1994; 94:804-9.

6. Kuhn JP. Imaging of the paranasal sinuses: Current status. J Allergy Clin Immunol 1986; 77:1, part 1:6-8.

7. Zinreich J. Imaging of inflammatory sinus disease. Immunol Allergy Clin North Am 1994; 14:17-29.

8. Raphael GD, Druce HM, Baraniuk JN, Kaliner M. Pathophysiology of rhinitis - Assessment of the sources of protein in methacholine-induced nasal secretions. Am Rev Respir Dis 1988; 138:413-20.

9. Noah TL, Henderson FW, Henry MM, Peden DB, Devlin RB. Nasal lavage cytokines in normal, allergic, and asthmatic schoolage children. Am J Respir Crit Care Med 1995; 152:1290-6.

10. Bascom R, Pipkorn U, Lichtenstein LM, Naclerio RM. The influx of inflammatory cells into nasal washings during the late response to antigen challenge. Am Rev Respir Dis 1988; 138:406-12. 
11. Cruz AA. Citologia quantitativa do lavado nasal: desenvolvimento de uma técnica simplificada e sua validação para o diagnóstico de rinite [tese]. Salvador: Faculdade de Medicina da Universidade Federal da Bahia, Pós-graduação em Medicina Interna; 1996.p.60-117.

12. Rothenberg ME. Mechanisms of disease - Eosinophilia. N Engl J Med 1998; 338:1592-600.

13. American Thoracic Society. Standardization of spirometry. Am J Respir Crit Care Med 1995; 152:1107-36.

14. National Asthma Education and prevention program committee. Guidelines for the diagnosis and management of asthma. National Institute of Health, Bethesda, MD; 1997.p.47-61.

15. Zinreich SJ. Rhinosinusitis: Radiologic diagnosis. Otolaryngol Head Neck Surg 1997; 117:S27-S34.

16. Newman LJ, Platts-Mills TAE, Phillips CD, Hazen KC, Gross CW. Chronic sinusitis: Relationship of computed tomographic findings to allergy, asthma, and eosinophilia. JAMA 1994; 271:363-7.

17. Naclerio RM, Meier HL, Sobotka AK, Adkinson NF, Meyers DA, Norman PS, Lichtenstein LM. Mediator release after nasal airway challenge with allergen. Am Rev Respir Dis 1983; 128:597-602.

18. Mahy BWJ, Kangro HO. Quantifying by cell counts. In: Virology methods manual. London: Academic Press; 1996. p.13-15.

19. Meltzer EO, Jalowayski AA. Nasal cytology in clinical practice. Am J Rhynology 1988; 2:1-8.

20. Pelikan Z, Pelikan-Filipek M. Role of nasal allergy in chronic maxillary sinusitis. Diagnostic value of nasal challenge with allergen. J Allergy Clin Immunol 1990; 86:484-91.

21. Rubin AS, Hetzel JL, Irion K. Radiologia das vias aéreas superiores em pacientes asmáticos. J Pneumol 1994; 20:1-5.

22. Zimmerman B, Stringer D, Feanny S, et al. Prevalence of abnormalities found by sinus X-rays in childhood asthma: Lack of relation to severity of asthma. J Allergy Clin Immunol 1987; 80:268-73.

23. Oliveira CAA, Solé D, Naspitz CK, Rachelefsky G. Improvement of bronchial hyperresponsiveness in asthmatic children treated for concomitant sinusitis. Ann Allergy Asthma Immunol 1997; 79:70-4.

24. Trippia SMG, Rosario NR, Ferrari FP. Aspectos clínicos da asma na criança: análise de 1009 pacientes de um ambulatório especializado. Rev Bras Alerg Imunopatol 1998; 21:75-82.

25. Kaliner MA, Osguthorpe D, Fireman P, et al. Sinusitis: Bench to bedside. J Allergy Clin Immunol 1997; 99:S829-S847.

26. Harlin BL, Ansel DG, Lane SR. A clinical and pathologic study of chronic sinusitis: the role of the eosinophil. J Allergy Clin Immunol 1988; 81:867-75.
27. Poulter LW, Norris A, Power C, Condez A, Burnes H, Schmekel, et al. $\mathrm{T}$ cell dominated inflammatory in the bronchioles of asymptomatic asthmatics are also present in the nasal mucosa. Postgrad Med J 1991; 67:747-53.

28. Malmberg H. Symptoms of chronic and allergic rhinitis and occurrence of nasal secretion granulocytes in university students, school children and infants. Allergy 1979; 34:389-94.

29. Marini M, Vittori E, Hollemborg J, Mattoli S. Expression of the potent inflammatory cytokines, granulocyte-macrophage colony stimulating factor and interleukin- 6 and interleukin-8, in bronchial epithelial cells of patients with asthma. J Allergy Clin Immunol 1992; 89:1001-9.

30. Bradding P, Feather IH, Wilson S, Bardin PG, Heusser CH, Holgate ST, et al. Immunolocalization of cytokines in the nasal mucosa of normal and perennial rhinitic subjects. J Immunol 1993; 151:3853-65.

31. Teran LM, Johnston SL, Schroder J, Church MK, Holgate ST. Role of nasal interleukin- 8 in neutrophil recruitment and activation in children with virus-induced asthma. Am J Respir Crit Care Med 1997; 155:1362-66.

32. Naclerio RM, Bartenfelder D, Proud D, Togias AG, Meyers DA, Sobotka AK, et al. Theophylline reduces histamine release during pollen-induced rhinitis J Allergy Clin Immunol 1986; 78:874-6.

33. Cook PR, Nishioka GJ. Allergic rhinosinusitis in the pediatric population. Otolaryngol Clin of North Am 1996; 29:39-55.

34. Lim MC, Taylor RM, Naclerio RM. The histology of allergic rhinitis and its comparison to cellular changes in nasal lavage. Am J Respir Crit Care Med 1995; 151:136-44.

Endereço para correspondência:

Dra. Loreni C.S. Kovalhuk

Rua Júlia Wanderley, 657

CEP 80430-030 - Curitiba, PR

E-mail:kovalhuk@softone.com.br 